\title{
The surgical anatomy of the conduction tissues
}

\author{
ROBERT H ANDERSON, SIEW YEN HO, ANTON E BECKER
}

From the Department of Paediatrics, Cardiothoracic Institute, Brompton Hospital, London; and the University of Amsterdam Department of Cardiovascular Pathology, Interuniversity Institute, Academic Medical Centre, Amsterdam, Holland

ABSTRACT On the basis of our collective experience we have reviewed the disposition of the cardiac conduction tissues as they might be observed by the surgeon in both normal and abnormal hearts. The sinus node lies subepicardially in the terminal sulcus; because of its variable blood supply the entire superior cavoatrial junction is a potential danger area. There are no morphologically discrete tracts extending through the atrial tissues between sinus and atrioventricular nodes. The atrioventricular node, the atrial extent of the atrioventricular conduction axis, is contained exclusively within the triangle of Koch. The axis penetrates through the central fibrous body and branches on the muscular ventricular septum immediately beneath the interventricular component of the membranous septum. The landmarks to these structures are described as they might be seen through the right atrium, left atrium, and aorta. Consideration is then given to the surgical anatomy of the abnormal muscular atrioventricular connections that underscore the ventricular pre-excitation syndromes. Finally, rules are developed whereby the disposition of the conduction tissues can be predicted with accuracy in congenitally malformed hearts, in the settings of both normal and abnormal chamber connections. The most important variables in this respect are alignment between the atrial and ventricular septal structures and the pattern of ventricular architecture present.

Understanding of the conduction tissues of the heart has had a chequered history since their discovery at the end of the last century. A contentious topic at their birth, they have continued to excite interest and disagreement up to the present time. Notwithstanding this, on one aspect all are agreed. If the cardiac surgeon is to leave the patient with a normally beating heart, he must be aware of the exact disposition of these tissues and his incisions, retraction, or suction must scrupulously avoid them. Equally, he must know the abnormal dispositions of these tissues as found in congenitally malformed hearts and must again treat these areas with considerable respect if he is to avoid postoperative arrhythmia, a particularly worrying complication of the surgical treatment of congenital heart disease. In this review we describe the anatomy of these tissues as we understand them, illustrating them as they will present to the surgeon at operation. We first

Address for reprint requests: Professor RH Anderson, Department of Paediatrics, Cardiothoracic Institute, Brompton Hospital, London SW3 6HP.

Accepted 9 February 1983 describe their disposition in the normal heart and then discuss rules for predicting their position in malformed hearts.

\section{Surgical anatomy of normal conduction tissues}

\section{THE SINUS NODE}

The sinus node, or pacemaker, is a small, cigarshaped structure which lies in the terminal groove, formed by the lateral junction of the superior caval vein with the remainder of the right atrium. Almost always the node lies in the groove to the right of the crest of the atrial appendage (as viewed with the heart in the surgical position-figure 1). It usually has an extensive tail which runs subepicardially in the groove towards the junction of the inferior caval vein with the atrium. The sinus node cannot be recognised unequivocally with the naked eye, but sometimes a whitish patch of tissue is visible in the groove at this site. The entire junction of the superior cava with the right atrium should, however, be treated with the utmost respect. This is because on occasion the sinus node can extend over the crest of the atrial appendage into the interatrial groove, a 


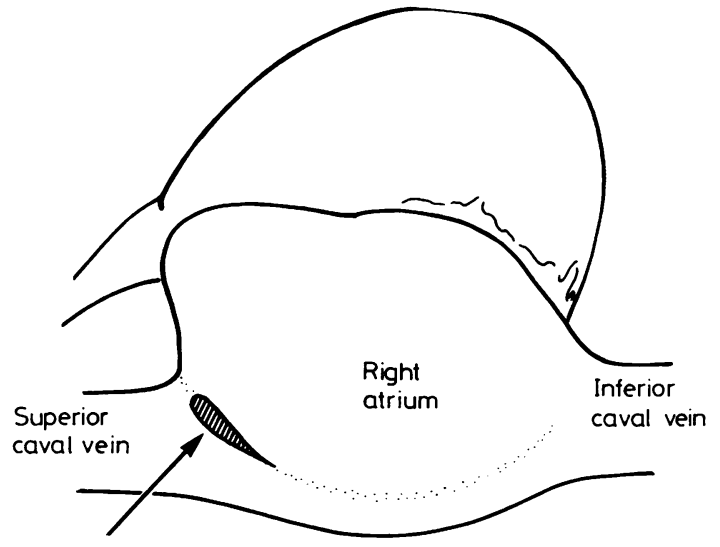

Sinus node in terminal groove

Fig 1 The usual position of the sinus node as it might be viewed by the surgeon operating from the right side of the operating table.

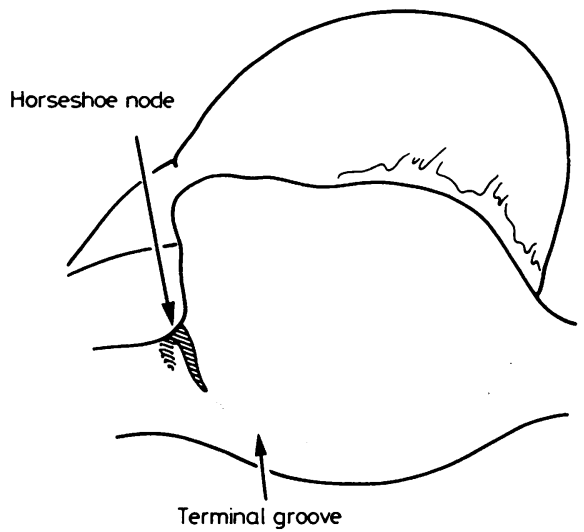

Fig 2 The occasional "horseshoe" position (about 10\% of cases) of the sinus node.

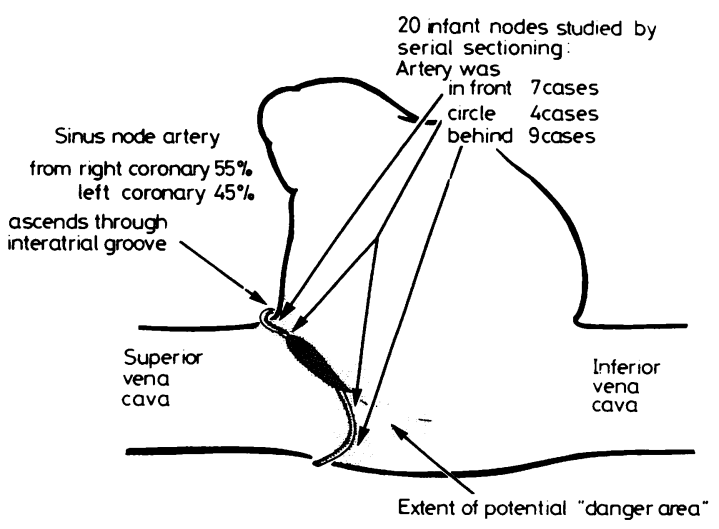

Fig 3 The variability in the course of the artery to the sinus node in relation to the superior cavoatrial junction. pattern described as usual by Hudson. ${ }^{1}$ We found this horseshoe arrangement (fig 2) to be the exception rather than the rule. ${ }^{2}$ Also of significance was the major variability we noted in the course of the nodal artery (fig 3 ). The prominent nodal artery originates from the origin of the right coronary artery in about $55 \%$ of cases and from the left coronary artery in the rest. ${ }^{3}$ We noted further variation in its course relative to the superior cava. It entered the terminal groove either in front of the cava or behind it, or else it formed an arterial circle around the cavoatrial junction. These patterns were not distinguishable with the naked eye. It therefore behoves the surgeon to treat the entire superior cavoatrial junction with the utmost respect if he is to avoid damage to the sinus node and postoperative arrhythmic sequelae. The entirety of the potential danger area is illustrated in figure 3 .

\section{THE INTERNODAL CONDUCTION MECHANISM}

The nature of the atrial myocardium between sinus and atrioventricular nodes has engendered more disagreement than any other part of the cardiac conduction mechanism. When it was discussed at length by the German Pathological Society in $1910,{ }^{4}$ the consensus was that the impulse was conducted between the nodes through plain atrial myocardium, there being no insulated and isolated tracts of conduction tissue extending between the nodes. Our results $^{5-7}$ completely endorse this original consensus. Those who have since postulated the existence of specialised tracts $^{89}$ have done so on the basis of finding scattered cells with histologically specialised characteristics among the broad bands of atrial myocardium between the nodes. Nowhere have these protagonists of "specialised internodal conduction" shown the existence of insulated conduction pathways comparable with the ventricular bundle branches, the latter being the paradigm of a conduction system. Furthermore, electrophysiological studies have shown that, from the standpoint of conduction, the sinus impulse passes to the atrioventricular node along broad fronts, ${ }^{10-12}$ the substrates for these fronts being determined by the overall geometry of the right atrium. ${ }^{13}$ The intraoperative mapping experiments of Wittig et al ${ }^{14}$ confirmed the existence of those broad fronts of atrial activity, particularly after excision of the atrial septum. They failed to show any narrow tracts responsible exclusively for the spread of excitation. This does not mean that the surgeon has freedom to make incisions at will in the atrial myocardium and then anticipate normal postoperative interatrial conduction. Although the mapping experiments militate against specialised conduction tracts, they do show that interatrial conduction occurs preferentially along 


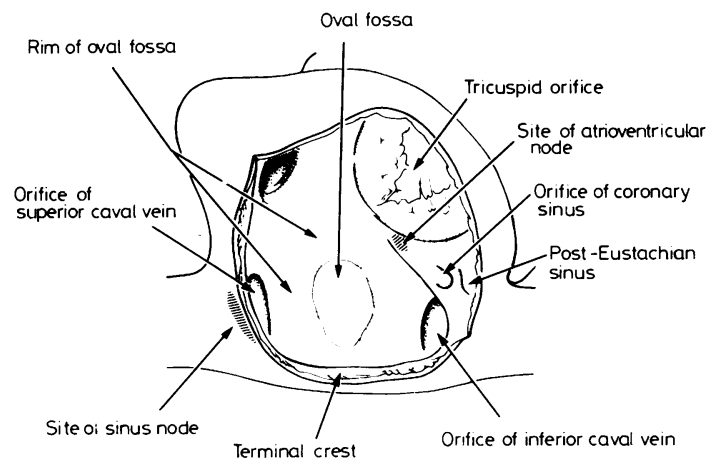

Fig 4 The anatomy of the right atrium is such that the venous orifices and oval fossa divide the myocardium into broad muscle bundles. These bundles, specifically the terminal crest and the margins of the oval fossa, act as the routes of preferential conduction between the sinus and atrioventricular nodes; and it makes sense to avoid these areas, as well as the sites of the node, during surgery.

the prominent muscle bundles, notably the terminal crest, the anterior lip of the oval fossa, and the sinus septum. These are the most direct routes between sinus and atrioventricular nodes (fig 4). If at all possible they should be preserved at operation. Certainly during atrial surgery great efforts should be made to keep one of those preferential routes intact if abnormal postoperative atrial conduction is to be avoided. ${ }^{14}$

\section{THE ATRIOVENTRICULAR NODE AND \\ PENETRATING BUNDLE}

The surgical landmarks to the atrioventricular node are those of the triangle of Koch (fig 5). If tension is placed on the Eustachian valve (when present), then the fibrous extension of this structure (the tendon of Todaro) can be traced into the sinus septum, where it can be seen extending leftwards and cephalad to insert into the central fibrous body. A triangle can then be constructed between the tendon of Todaro, the attachment of the septal leaflet of the tricuspid valve to the septum, and the orifice of the coronary sinus. The atrioventricular node and its transitional cell zones are contained entirely within this triangle. If the tendon of Todaro cannot be identified the middle of the sinus septum can be taken as the atrial boundary of the triangle.

The penetrating bundle passes through the central fibrous body at the apex of the triangle of Koch, perforating the fibrous tissue to pass directly into the left ventricular outflow tract. In this position the bundle is more or less directly related to the mitral, tricuspid, and aortic valves and the membranous septum and is at risk during surgery on any of these structures. The overall anatomy and interrelation-

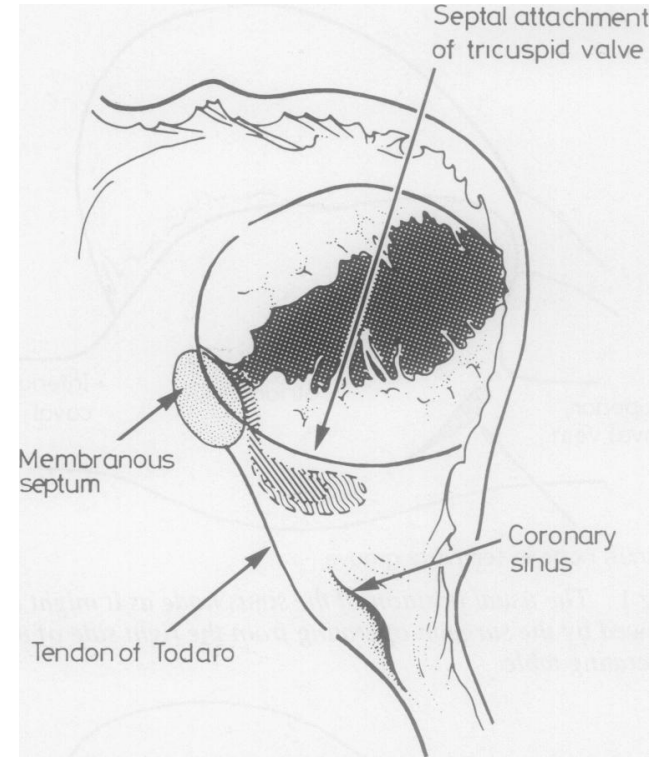

Fig 5 Landmarks of the triangle of Koch as viewed by the surgeon.

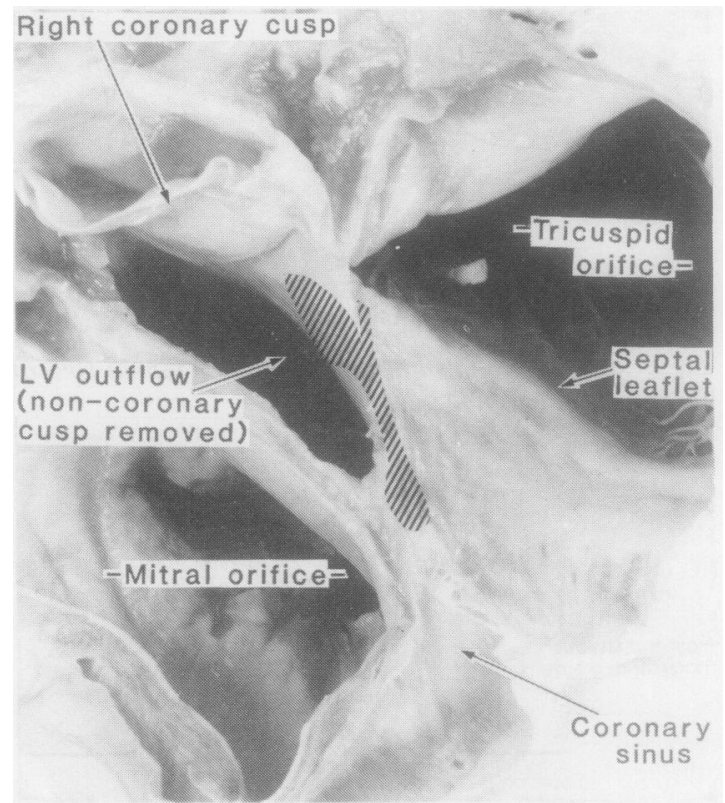

Fig 6 Dissection viewed in surgical orientation showing the relationships of the atrioventricular node and bundle to the aortic, mitral, and tricuspid valve rings.

ships of these structures and the penetrating bundle are shown in the dissection in figure 6. From the surgical standpoint, the left atrial landmark to this 


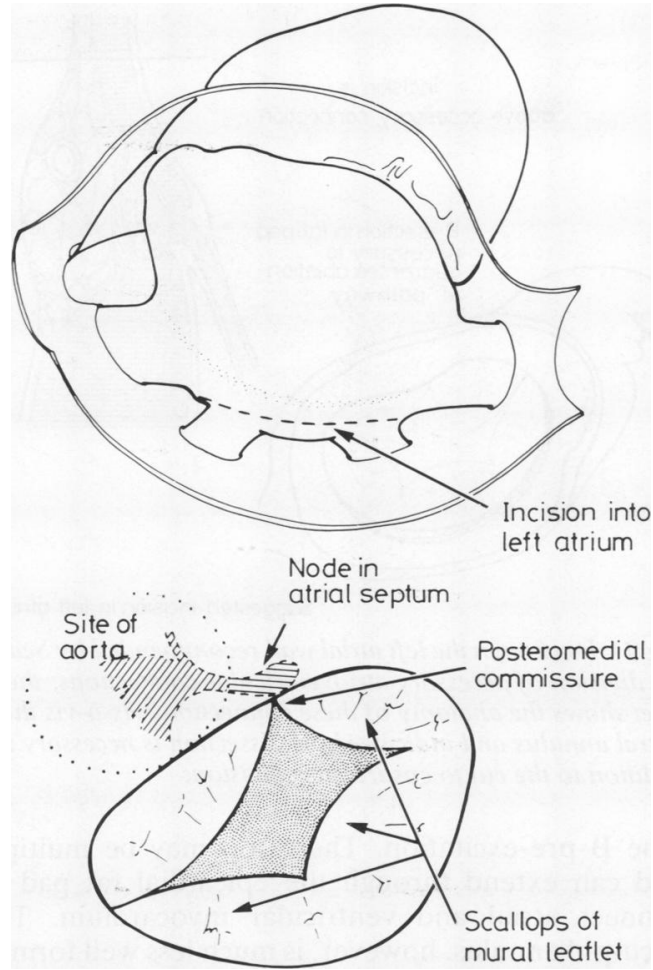

Fig 7 Relationship of the atrioventricular node and bundle to the mitral valve as seen by the surgeon approaching through the left atrium.

area is above and cephalad to the posteromedial commissure of the mitral valve (fig 7). As seen from the tricuspid valve, the danger-area is between the apex of the triangle of Koch and the anteroseptal commissure. As viewed through the aorta, the danger area is directly beneath the commissure between the non-coronary and right coronary aortic leaflets (fig 8).

\section{VENTRICULAR CONDUCTION TISSUES}

In contrast to the atrial conduction mechanism, there is no doubt that an insulated conduction system distributes the cardiac impulse through the ventricles. Cutting this ventricular system abolishes conduction through it. Having penetrated into the subaortic outflow tract, the atrioventricular bundle divides into right and left bundle branches. Although usually situated astride the muscular ventricular septum, between it and the membranous septum, the division can occur on the left ventricular aspect of the septum. ${ }^{15}$ The branching occurs along a length of the bundle, the left bundle branches tumbling down the smooth left side of the septum, while the right bundle branch continues in the general

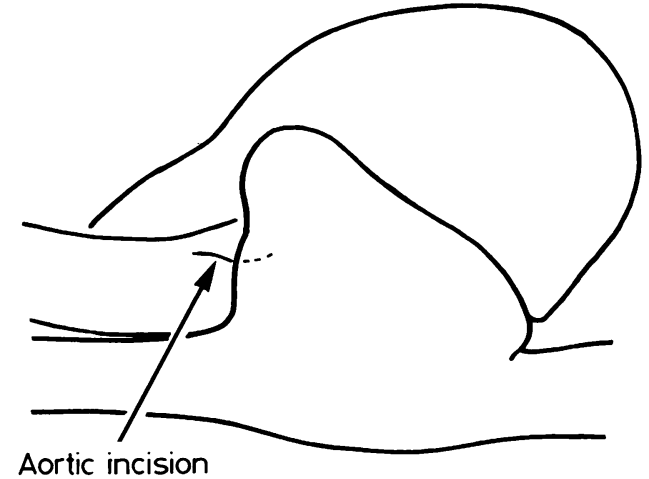

Right coronary leaflet

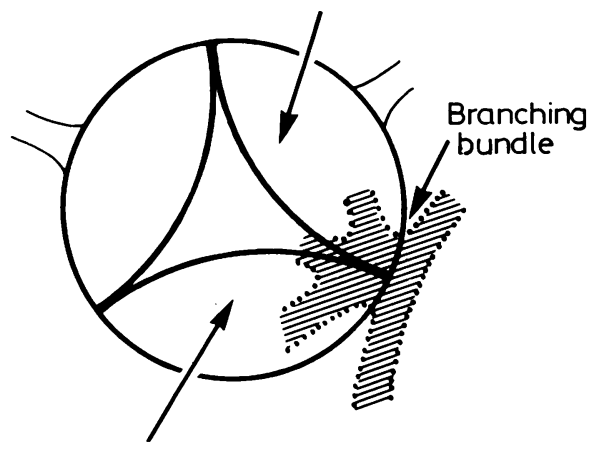

Non-coronary leaflet

Fig 8 Relationships of the ventricular conduction tissues to the aortic valve as viewed by the surgeon approaching via an aortotomy.

direction of the axis of the node, penetrating the branching bundles. Three major divisions (anterior, septal, and posterior) can be made out in the descending fan of left bundle-branch cells, but the three are intimately interconnected.

In contrast to the fan-like left bundle branch, the right bundle branch is a narrow, cord-like structure. It generally passes intramyocardially to reach the right side of the septum, running through the posterior limb of the septomarginal trabecula and passing beneath the medial papillary muscle complex. It then extends to the right ventricular apex within the body of the trabecula, ramifying at the ventricular apex.

\section{Surgical anatomy of congenitally malformed con- duction tissues}

The conduction tissues can themselves be the sub- 
ject of congenital lesions, such as congenitally complete heart block or ventricular pre-excitation. Alternatively, the conduction tissues can be anatomically normal but be disposed in abnormal fashion because of congenital lesions of the heart itself Although congenitally complete heart block is of relatively little importance surgically, the conduction tissues in ventricular pre-excitation and congenital malformations themselves are of major importance.

\section{Surgical anatomy of ventricular pre-excitation}

Ventricular pre-excitation can be produced by several anatomical substrates, the commonest being particularly amenable to surgical treatment. ${ }^{16}$ Preexcitation of the Wolff-Parkinson-White type (short PR-broad QRS-delta wave) is produced by accessory atrioventricular connections, which can readily be divided by surgical operation. The rarer form of Wolff-Parkinson-White syndrome, which is due to accessory nodoventricular or fasciculoventricular fibres ("Mahaim" fibres) is not in itself amenable to surgical treatment, but may on occasion require treatment by division of the atrioventricular bundle. This is probably best done by cryothermy, ${ }^{17}$ the landmarks of the triangle of Koch being used as the guide to the penetrating bundle. Pre-excitation of the Lown-Ganong-Levine variety (short PRnormal QRS) is due either to atriofascicular fibres or to intranodal bypass tracts. As yet, surgical treatment in these cases is confined to division of the penetrating bundle in cases of intractable tachycardia. It is therefore the classical Wolff-ParkinsonWhite type of pre-excitation which will most frequently require surgical treatment. Here knowledge of the anatomy of accessory atrioventricular connections greatly facilitates their successful surgical division.

Accessory atrioventricular connections can be located around the mitral orifice, around the tricuspid orifice, or within the septum itself. Left-sided mitral connections generally produce so-called type A pre-excitation and have a particularly constant morphology. They take their origin from the atrial myocardium just above the mitral annulus and then run through the epicardial fat pad on the outside of the annulus, hugging it very closely, before inserting into the ventricular myocardium. An incision placed in the atrial wall above the annulus will not divide a left-sided connection (fig 9). Dissection in the fat pad on the epicardial aspect of the annulus will be necessary to ablate the connection. It should also be borne in mind that these connections may be multiple.

Right-sided connections usually produce so-called

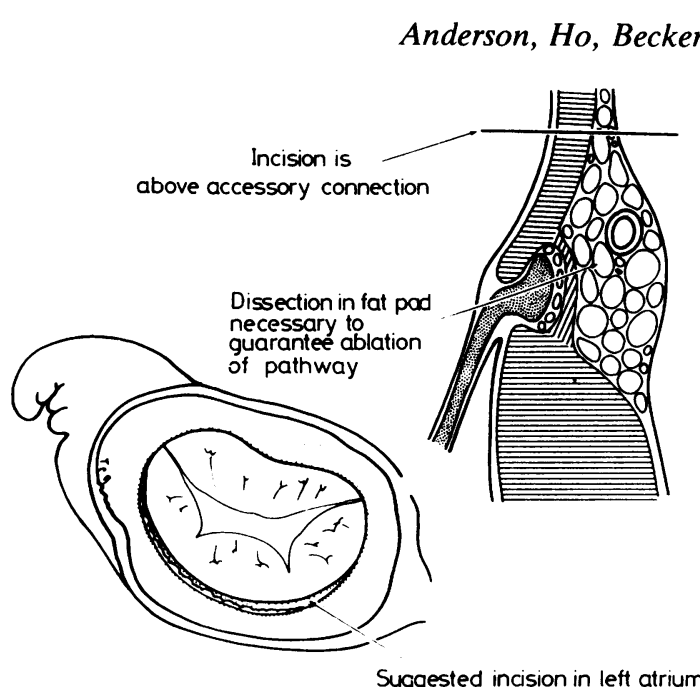

Fig 9 Incision in the left atrial wall recommended by Sealy for division of accessory atrioventricular connections; the inset shows the anatomy of these connections vis-à-vis the mitral annulus and indicates how dissection is necessary in addition to the cut to ensure their division.

type B pre-excitation. These too may be multiple and can extend through the epicardial fat pad to connect atrial and ventricular myocardium. The tricuspid annulus, however, is much less well formed than the mitral and these connections can traverse subendocardially through deficiencies in the annulus. None the less, an incision on the annulus with dissection in the epicardial fat pad is usually necessary to be sure of achieving division of a rightsided connection.

Septal accessory connections are the most difficult to treat, in terms both of localisation and of surgical division. ${ }^{18}$ Here use can be made of the tissue plane that extends beneath the coronary sinus towards the atrioventricular node. ${ }^{6}$ Access to this plane can be obtained from the right atrium and then the atrial septal myocardium can be liberated from the ventricular myocardium with disruption of any accessory connections between. Even in the most expert hands, however, these connections are the most difficult to disrupt. In refractory cases division of the atrioventricular bundle may be required.

\section{Conduction tissues in malformed hearts}

\section{ATRIAL CONDUCTION TISSUES}

Very rarely is the sinus node shifted from its normal position in the terminal groove. The only occasions on which we have encountered an abnormally located sinus node are in association with juxtaposition of the atrial appendages ${ }^{19}$ and in left atrial isomerism ("situs ambiguus with polysplenia" ${ }^{20}$ ). 
These occasions are likely to be rare in surgical practice. Atrial arrhythmias are, however, well known to be frequent after atrial surgery, particularly in the treatment of complete transposition. Although this complication has been attributed to damage to "specialised pathways," as we have indicated above, conduction between the nodes occurs through plain atrial myocardium. The careful studies of Gillette and his colleagues ${ }^{21}$ have shown that almost always these arrhythmias result from sinus node damage, while Ullal et $\mathbf{l}^{22}$ have demonstrated that scrupulous avoidance of the sinuatrial junction can effectively abolish postoperative arrhythmias after Mustard's operation for complete transposition. The secret of avoidance of atrial arrhythmias is therefore to be aware of the danger area of the sinuatrial junction and to avoid it meticulously during all surgical procedures.

\section{VENTRICULAR CONDUCTION TISSUES}

The ventricular conduction tissues are most at risk during repair of ventricular septal defects. We will describe the relationship of defects and conduction tissues both when the atrioventricular node is normally sited and when it is found in abnormal sites.

\section{Malformations with normally situated atrioventricu- lar nodes}

"Isolated" ventricular septal defect In all hearts with atrioventricular concordance and in those hearts with ambiguous atrioventricular connection and right-hand pattern (d-loop) ventricular architecture ${ }^{20}$ the atrioventricular node is normally sited at the apex of the triangle of Koch irrespective of the presence of defects elsewhere in the heart. This encompasses the great majority of lesions requiring surgical treatment. In these patients therefore the guides to the atrioventricular node and the penetrating atrioventricular bundle are the landmarks of the triangle of Koch as described above. The guides to

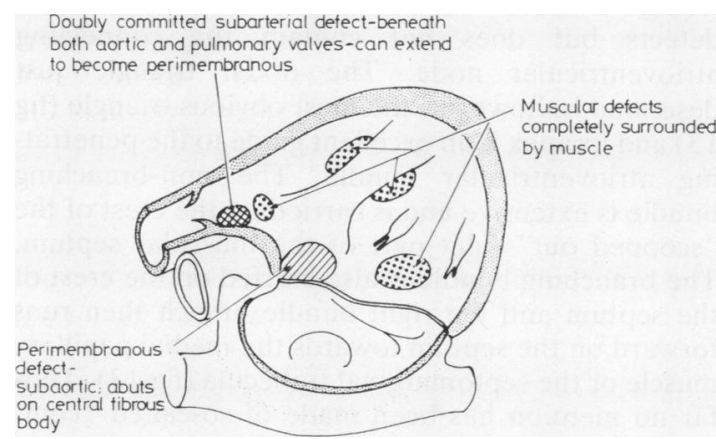

Fig 10 The basic subdivision of ventricular septal defects as viewed by the surgeon.

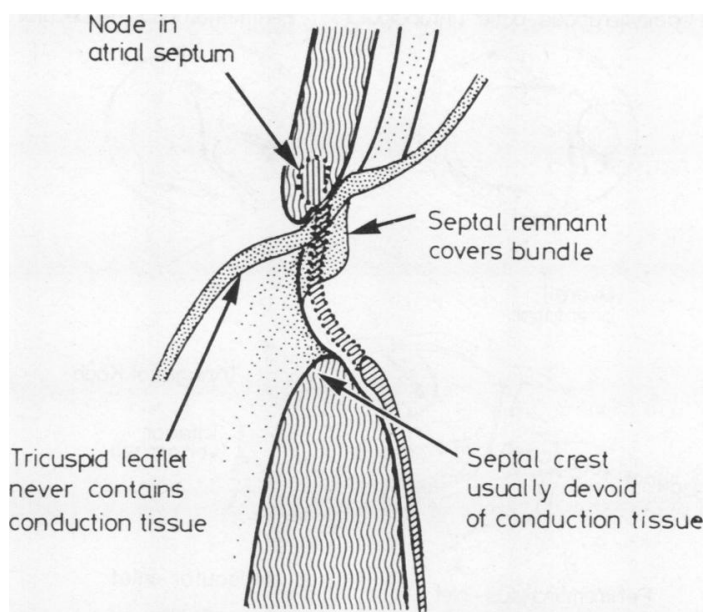

Fig 11 The usual relationship of the non-branching bundle to the crest of the muscular septum in the presence of a ventricular septal defect; it is always safe to place stitches in the leaflet tissue of the tricuspid valve.

the ventricular conduction tissue depend on the type of ventricular septal defect present. Irrespective of the ventriculoarterial connection found in tearts with ventricular septal defects, the defects can be divided into three types: perimembranous, muscular, and doubly committed subarterial ${ }^{23}$ (fig 10). The disposition of conduction tissue varies in these, but basically depends on whether a defect is perimembranous or muscular. A perimembranous defect is characterised by the fact that the defect abuts on the central fibrous body and part of its rim is formed by the atrioventricular component of the membranous septum and the aortic valve. This atrioventricular component of the membranous septum is the major danger area of these defects, since it is the site of the penetrating bundle. When approached from either right atrium or right ventricle this part of a perimembranous defect will be overlaid by the leaflets of the tricuspid valve. The free leaflet tissue of the tricuspid valve never harbours conduction tissue. The rule of safety therefore is to place sutures in this area through the leaflet tissue and not through its attachment. In this way it will be impossible to damage the penetrating atrioventricular bundle (fig 11). In hearts with ventricular septal defects almost always there is a segment of non-branching atrioventricular bundle between penetrating and branching bundles and always in perimembranous ventricular septal defects this non-branching bundle is to the right hand of the surgeon when he is approaching through the atrium (fig 12). The proximity of non-branching and branching bundles to the crest of the septum depends on the precise type of 


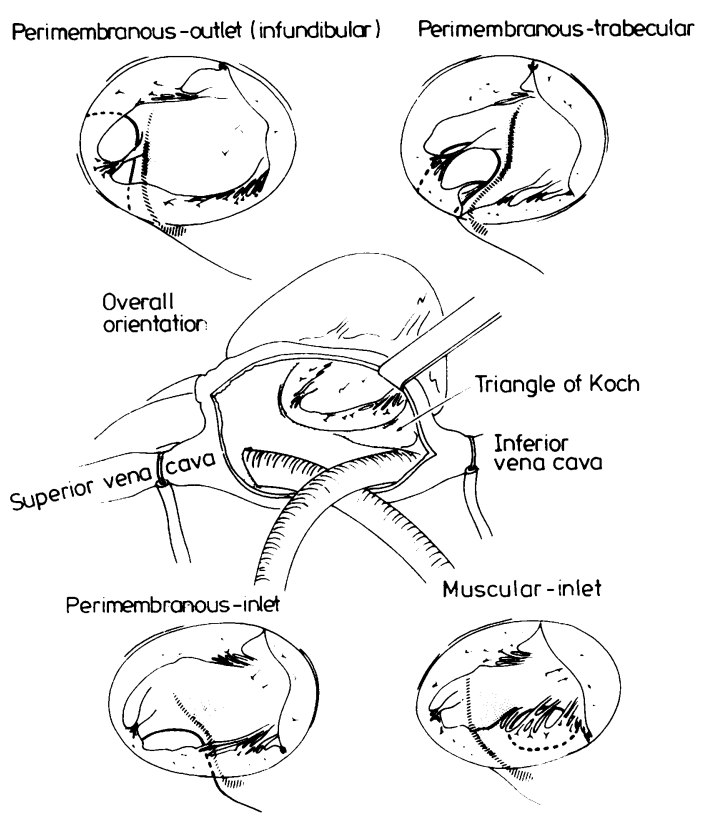

Fig 12 Disposition of the ventricular conduction tissues in the different types of ventricular septal defect as viewed by the surgeon through a right atriotomy.

perimembranous defect encountered. ${ }^{24}$ When the defect extends into the inlet septum the bundles are much closer to the septal crest than when the defect extends into the ventricular outlet regions.

In muscular defects, the entire rim of the defect is muscular and so the penetrating bundle is no longer vulnerable. The danger area in a muscular defect therefore depends on its position within the septum. The muscular defect in which the bundle is most at risk is one in the inlet part of the septum which extends up towards the valve annuli but does not reach the central fibrous body, being separated from it by a muscular rim. In these muscular inlet defects the conduction tissue axis is to the left hand of the surgeon approaching through the atrium. In other words, it is precisely to the opposite side as seen in a perimembranous defect (fig 12). For this reason it is essential to distinguish perimembranous and muscular inlet defects.

Muscular trabecular defects are well distant from the central fibrous body and the proximal ventricular conduction tissues. They are therefore relatively safe from the risk of heart block, the only danger being peripheral damage with proximal "tracking" of haemorrhage and exudate. ${ }^{25}$ Defects in the outlet region with muscular inferior rims are the safest from the standpoint of conduction tissues. In these defects the posterior limb of the septomarginal trabecula fuses into the ventriculoinfundibular fold and forms a muscle bundle that separates the central fibrous body from the right ventricular aspect of the defect. It also protects the conduction tissues. In all hearts with a muscular rim separating the central fibrous body from the defect therefore the conduction tissues are safe from all but the most deeply placed sutures. This rule holds good for doubly committed subarterial defects with muscular inferior rims (we define a subarterial defect as one beneath both aorta and pulmonary valves-hence its doubly committed nature). It does not apply when a doubly committed subarterial defect extends to become perimembranous. These rules for conduction tissue disposition in perimembranous, muscular, and doubly committed subarterial defects hold good also for malformations with abnormal ventriculoarterial connections such as double-outlet right ventricle and complete transposition.

Atrioventricular septal defects The septal deficiency in an atrioventricular septal defect ("atrioventricular canal malformation," "endocardial cushion defect") affects primarily the atrioventricular junction. There is an extensive deficiency of the inlet part of the muscular ventricular septum, and although the atrial septum is frequently well formed the atrial septum makes contact with the ventricular septum only at the anterior and posterior margins of the atrioventricular junction-unlike in the normal heart, or hearts with isolated ventricular septal defects, where there is usually a more extensive area of septal atrioventricular contiguity. This lack of septal contiguity determines the conduction tissue disposition. The atrioventricular node is situated well posterior in the atrial septum just above its posterior connection with the atrioventricular junction. A nodal triangle is formed between the lower rim of the atrial septum (roof of the "ostium primum atrial septal defect") and the posterior attachment of the atrioventricular valve and the coronary sinus. This nodal triangle is not the triangle of Koch. The triangle of Koch does exist in atrioventricular septal defects but does not contain the connecting atrioventricular node. The nodal triangle just described is, however, the most obvious triangle (fig 13) and its apex is an excellent guide to the penetrating atrioventricular bundle. The non-branching bundle is extensive and is carried on the crest of the "scooped out" inlet part of the muscular septum. The branching bundle is also carried on the crest of the septum and the right bundle branch then runs forward on the septum towards the medial papillary muscle or the septomarginal trabecula (fig 13). Thus far no mention has been made of so-called "complete" versus "partial" atrioventricular septal defects. This is because the conduction tissue dispos- 


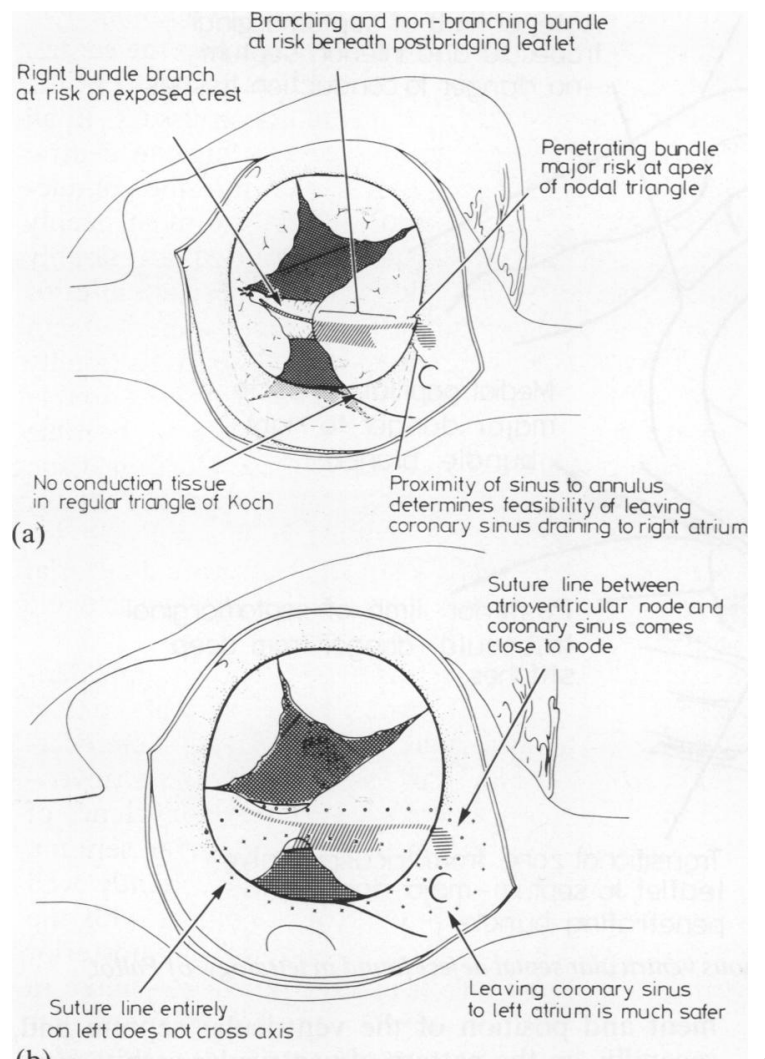

(b)

Fig 13 Basic disposition of the conduction tissues in atrioventricular septal defects as viewed by the surgeon through a right atriotomy: (a) shows the arrangement with a common orifice and $(b)$ the arrangement with separate right and left valve orifices. The possible suture lines are indicated.

ition is essentially the same in the two subgroups. The difference is that in defects with a common atrioventricular valve the right bundle branch is exposed on the "bare" area of septum found between the facing edges of the anterior and posterior bridging leaflets. The non-branching and branching segments of the axis are covered by the posterior bridging leaflet. In those defects in which a connecting leaflet tongue produces separate right and left atrioventricular orifices ("ostium primum atrial septal defects") the tongue also covers the septal crest so that the entire conduction axis is hidden from the surgeon by valve leaflet tissue (fig 13).

Tetralogy of Fallot As in hearts with an isolated ventricular septal defect, the defect in tetralogy of Fallot can be subdivided into perimembranous, muscular, and doubly committed subarterial forms; and the conduction tissue disposition is as described

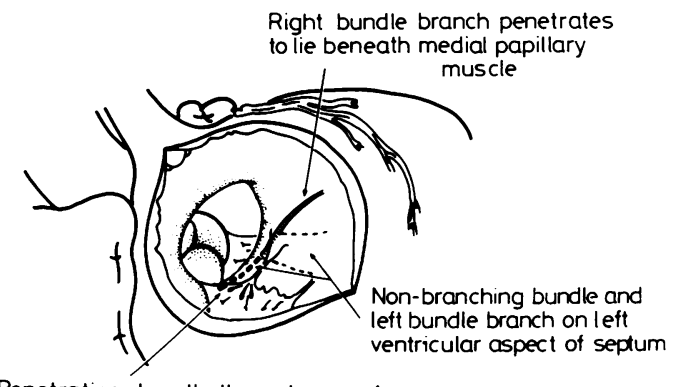

Penetrating bundle through area of tricuspid-aortic fibrous continuity

Right bundle branch at risk

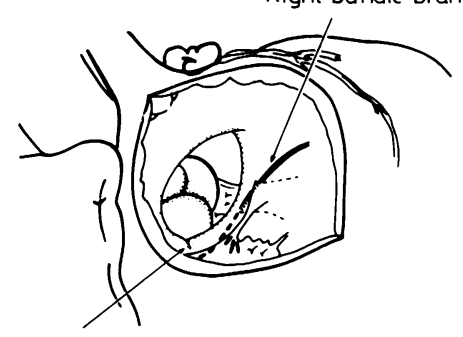

Ventriculo-infundibular fold fuses with

septomarginal trabecula-safe conduction axis

Fig 14 The distribution of conduction tissues in tetralogy of Fallot varies according to the type of defect present: the upper panel shows the arrangement with a perimembranous defect and the lower panel the much safer disposition when there is a muscular posteroinferior rim.

for the basic defects. Most defects are perimembranous in position-that is, they abut directly on the central fibrous body. They frequently possess membranous septal remnants in their posteriorinferior quadrants. The danger area is the segment of aorto-mitral-tricuspid continuity where the axis penetrates. The rule that tricuspid valve leaflet tissue never harbours conduction tissue should again guide suture placement. Usually the non-branching and branching bundles descend on the left ventricular aspect of the septum (fig 14), so the crest of the septum itself is devoid of conduction tissue. But on occasion the branching bundle may be found astride the septum, ${ }^{26}{ }^{27}$ so it is probably safer always to place right ventricular sutures away from the actual crest. Figure 15 illustrates these danger points and other areas around the defect in which the surgeon may be confronted by problems because of the anatomical arrangement.

In about a fifth of cases of tetralogy the posterior limb of the septomarginal trabecula fuses with the ventriculoinfundibular fold to produce a muscular outlet defect. As with isolated defects, the muscle bar thus formed protects the conduction axis and the entire muscular rim of the defect is a safe area (fig 14 , lower panel). A much rarer variant of tetralogy 


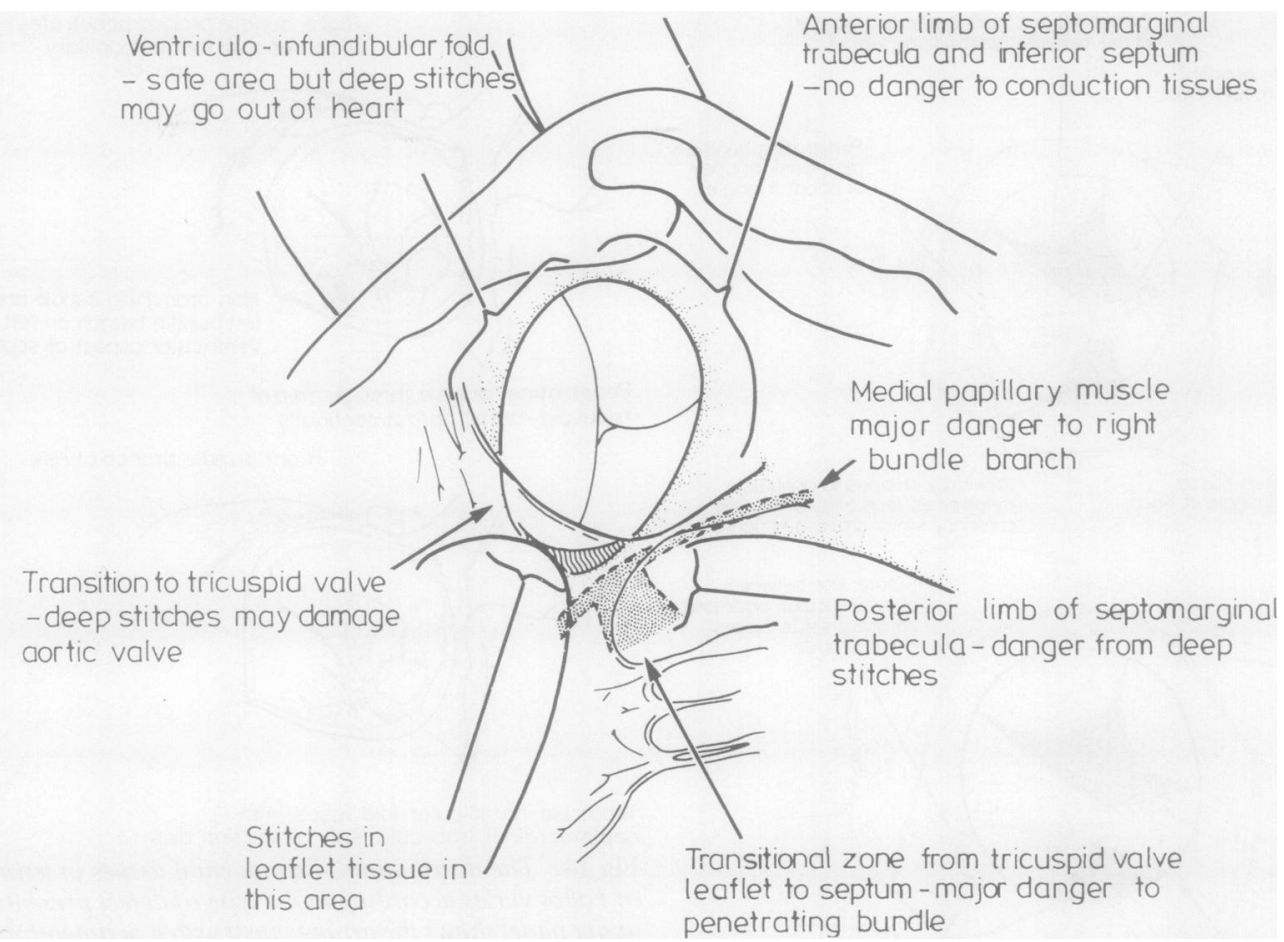

Fig 15 Anatomical danger areas of the typical perimembranous ventricular septal defect found in tetralogy of Fallot.

is when the infundibular (outlet) septum is itself absent or grossly deficient. The important point then with regard to the conduction tissue is whether the doubly committed subarterial defect thus produced extends to become perimembranous or has a muscular inferior rim. The conduction tissues will be much more at risk should the defect extend to be perimembranous.

Malformations with abnormally located atrioventricular nodes

The hearts that possess abnormally located atrioventricular nodes are those with atrioventricular discordance, those hearts with ambiguous atrioventricular connection that also have a left-hand (l-loop) pattern of ventricular architecture, and hearts with univentricular atrioventricular connection to a morphologically left or indeterminate ventricle. Some hearts with univentricular atrioventricular connection to a morphologically right ventricle with a right-sided rudimentary left ventricle also have abnormal nodes, but these are exceedingly rare and are discussed elsewhere. ${ }^{28}$ Finally, hearts with a straddling tricuspid valve have abnormally located nodes. $^{29}$

The rules which govern the location of the atrioventricular node depend, firstly, on the align- ment and position of the ventricular septum and, secondly, on the pattern of ventricular architecture. The orientation of the ventricular septum is important because the trabecular septum carries the ventricular conduction tissues. The atrioventricular node is developed from the embryonic atrioventricular canal musculature. Hence abnormal hearts have the potential to develop an atrioventricular node wherever the trabecular septum makes contact with the atrioventricular junction (fig 16). A normally sited node is developed only when the muscular ventricular septum extends to the crux cordis and is

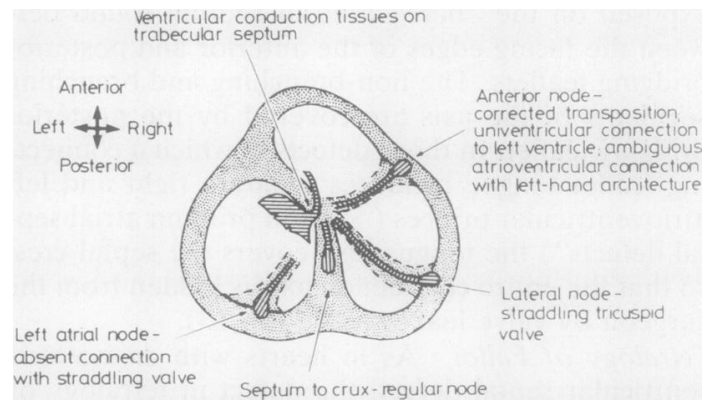

Fig 16 An atrioventricular node can be formed at any point round the atrioventricular junction where the trabecular septum makes contact with the junction. 


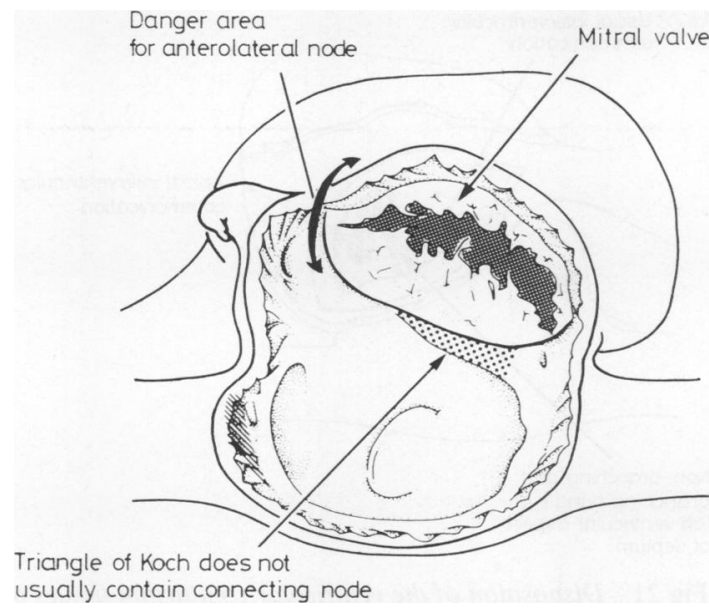

Fig 17 Position of the connecting atrioventricular node in congenitally corrected transposition as viewed through a right atriotomy.

normally aligned relative to the atrial septum.

Congenitally corrected transposition Congenitally corrected transposition is the combination of atrioventricular discordance and ventriculoarterial discordance. When this segmental arrangement is found with usually arranged atrial chambers (solitus), the ventricular septum extends to the crux cordis. But it is not in alignment with the atrial septum because of the wedged position of the pulmonary outflow tract. The normal node is unable to make contact with the ventricular conduction tissues. Instead, a node situated anterolaterally in the right atrioventricular orifice beneath the aditus to the atrial appendage takes over as the connecting atrioventricular node (fig 17). When there is a coexisting ventricular septal defect that is viewed through a ventriculotomy, the non-branching bundle is seen to encircle anteriorly around the pulmonary valve and then to descend cephalad to the defect (fig 18). In some examples of congenitally corrected transposition with usual atrial arrangement, however, there is better alignment between atrial and inlet ventricular septa. Then both normally sited and anomalous nodes can make contact with the ventricular conduction tissues, producing a "sling" of conduction tissue. ${ }^{30}{ }^{31}$ In congenitally corrected transposition with mirror-image atrial chambers (inversus), there is almost always good alignment between atrial septum and inlet ventricular septum. Despite the atrioventricular discordance, a normally sited connecting node is then the rule. ${ }^{32} 33$

Ambiguous atrioventricular connection An ambiguous atrioventricular connection is found when there are isomeric atrial chambers ("situs ambiguus") and each atrium connects to its own

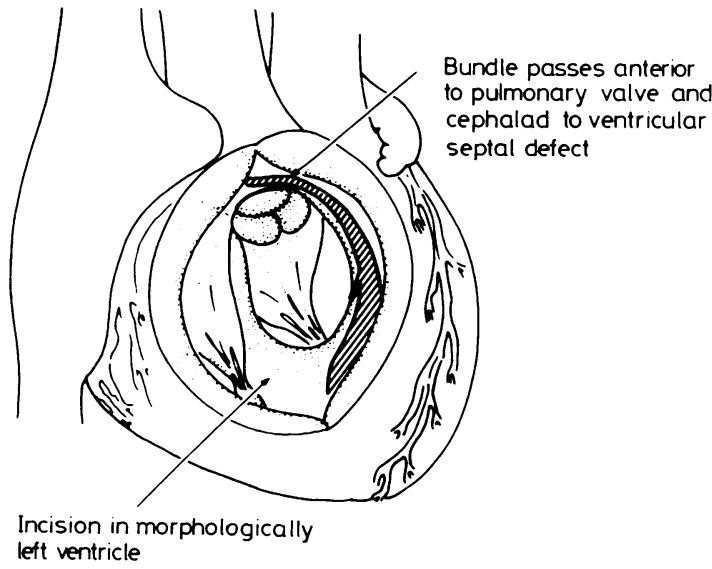

Fig 18 Disposition of the ventricular conduction tissues in congenitally corrected transposition as viewed via a ventriculotomy in the morphologically left ventricle.

ventricle. Then the septum extends to the crux but the atrial septum is often deficient because frequently there is a coexisting atrioventricular septal defect, usually with a common atrioventricular orifice. In these circumstances it is the pattern of ventricular architecture which determines the disposition of the ventricular conduction tissues. When there is a right-hand pattern ("d-loop") a normally situated atrioventricular node is formed. When there is a left-hand pattern ("l-loop") there is either an anomalous anterolateral connecting node or else

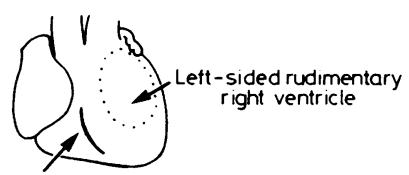

Incision in left ventricle

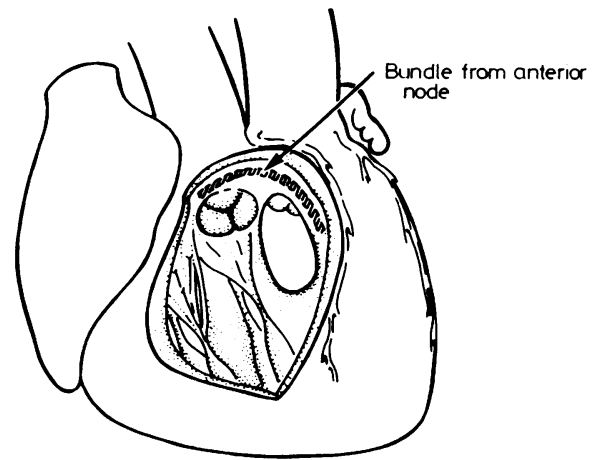

Fig 19 Disposition of conduction tissues in double-inlet left ventricle with a left-sided rudimentary right ventricle as viewed through an incision in the main ventricular chamber. 


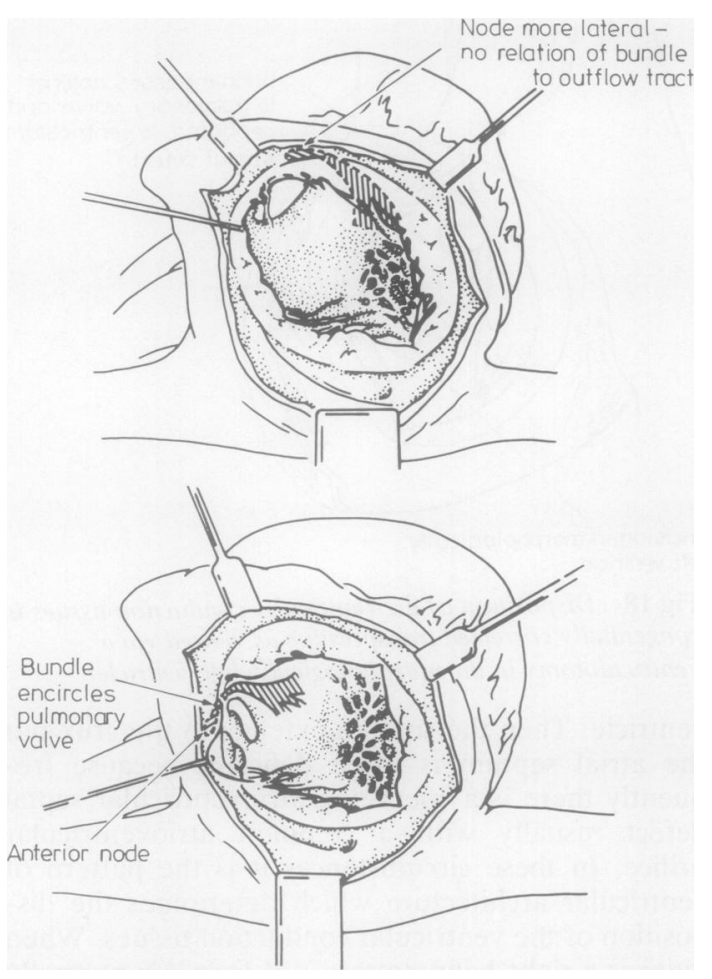

Fig 20 Disposition of conduction tissues in double-inlet left ventricle with right-sided (upper drawing) and left-sided (lower drawing) rudimentary right ventricle as viewed through a right atriotomy.

a sling of conduction tissue. ${ }^{20}$ These patterns are found irrespective of the presence of right isomerism ("asplenia") or left isomerism ("polysplenia").

Hearts with univentricular atrioventricular connection In those hearts in which the atrial chambers connect with only one ventricle, the orientation of the trabecular septum when present is the major determining feature. In hearts with a double-inlet left ventricle ("single ventricle with outlet chamber") the septum never reaches to the crux. Thus whether the rudimentary right ventricle is right sided or left sided there is always an anomalous anterolateral atrioventricular node. ${ }^{34}$ The position of the rudimentary ventricle affects only the relationship of the non-branching bundle to the pulmonary valve (if we assume the presence of ventriculoarterial discordance) ${ }^{35}$ When the rudimentary ventricle is left sided the bundle encircles the pulmonary valve to reach the trabecular septum (fig 19). When the rudimentary right ventricle is right sided the bundle descends directly on to the septum, shown in figure 20 as it would be viewed through an

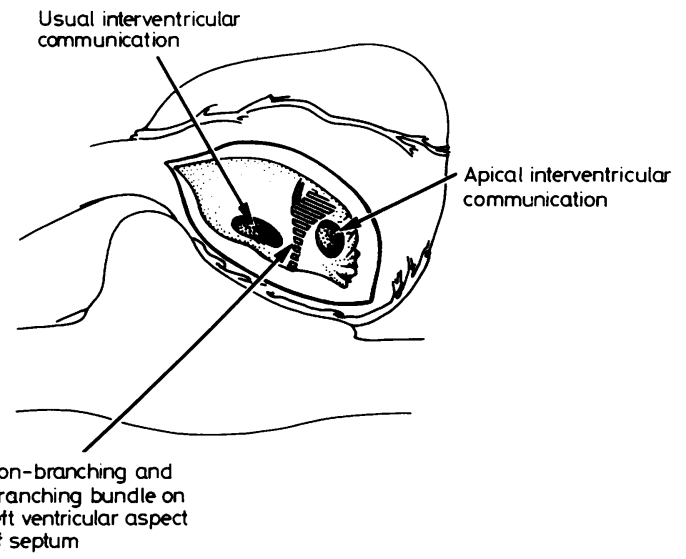

Fig 21 Disposition of the ventricular conduction tissues in relation to the interventricular communication in hearts with the atria connected only to the left ventricle as seen from the rudimentary right ventricle. The non-branching and branching bundles are carried on the left ventricular aspect of the septum and so are away from the operative field. They pass beneath the usual interventricular communication but would be superior to the rare apical defect. Only the terminal part of the right bundle branch is immediately subendocardial in the rudimentary ventricle.

atriotomy and compared with a heart with a leftsided rudimentary ventricle. The important point is that if the approach is from the rudimentary right ventricle (fig 21) the bundle will always be beneath the interventricular communication. The same rules hold good for classical tricuspid atresia. In this anomaly the atria connect only to the left ventricle because the right atrioventricular connection is absent. ${ }^{36}$ Because the tricuspid orifice is absent there cannot be an anterior and a normally sited node and there is only a conglomerate mass of nodal tissue in the floor of the blind-ending right atrium (fig 22). But when seen from the rudimentary right ventricle the ventricular conduction tissues are the same as are found with a double-inlet left ventricle. Here it is important to distinguish the usual communication from an apical muscular trabecular defect. The bun- N dle will pass beneath the usual defect but above a muscular trabecular defect (fig 21). This must be $\mathrm{N}$ remembered if a defect is to be enlarged surgically in $\omega$ tricuspid atresia with ventriculoarterial discordance.

In hearts with a solitary indeterminate ventricle there is no ventricular septum. An anomalous $\mathbb{D}$ atrioventricular node is therefore the rule. Usually this will be anterolateral and the bundle will descend laterally into the ventricular wall. Very frequently, $\stackrel{\circ}{\mathbb{D}}$ however, large free-running trabeculae are found in the ventricles of these hearts. When these trabeculae $\stackrel{\Phi}{\varrho}$ extend to the atrioventricular junction they may 


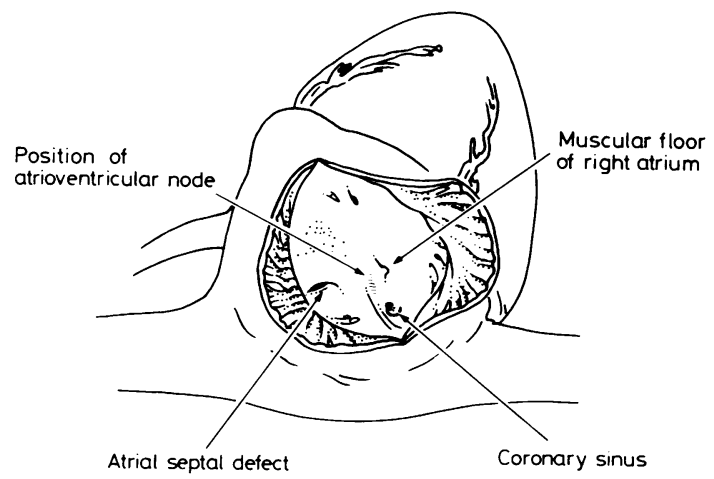

Fig 22 Surgeon's view of the right atrial floor in classical tricuspid atresia showing the position of the atrioventricular node.

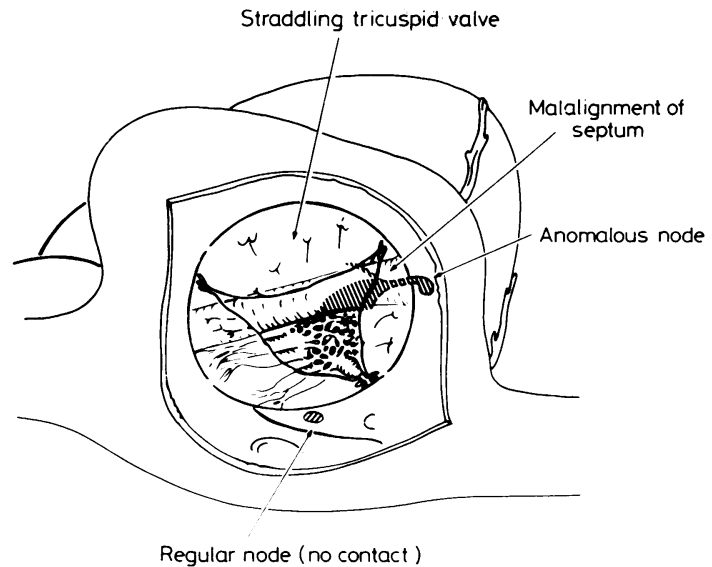

Fig 23 Disposition of the conduction tissue axis in a heart with atrioventricular concordance and straddling tricuspid valve as viewed through a right atriotomy.

carry the conduction tissues, either from an anterior node or on occasion from a normally situated node. ${ }^{3738}$ It is also important to distinguish hearts with a solitary indeterminate ventricle from hearts with huge ventricular septal defects. In the latter anomaly a rudimentary ventricular septum will be found extending to the crux. Because of this there will be a normally sited node and conduction tissues.

Straddling tricuspid valve In hearts with straddling of a normally positioned tricuspid valve the degree of override of the straddling valve can vary considerably. When the valve is primarily connected to the morphologically left ventricle the heart in essence has a double-inlet left ventricle and we categorise it as such. Then, as described above, an anomalous node is to be expected and is indeed present. But when the overriding tricuspid valve is connected mostly to the morphologically right ventricle the atrioventricular connection is concordant. A nor- mally sited node would then be anticipated. The paramount feature, however, is the orientation of the septum away from the crux. In these circumstances an anomalous node is formed, albeit sometimes posterior to the normal node (fig 23).

\section{Conclusions}

With relatively few rules, the surgical disposition of the conduction tissues can be anticipated not only in normal hearts but also in congenitally malformed hearts. The rules demand attention to the sequential segmental arrangement, particularly the morphology of the atrioventricular junction and the orientation of the ventricular septum. These guides, however, are at best rules and not immutable laws. As expected with rules, they will lead to correct decisions in most cases. But if there is any suspicion of a departure from the rules it is always wise to check conduction tissue disposition with intraoperative identification.

Two of us (RHA and SYH) are supported by grants from the British Heart Foundation. We are indebted to all our friends, colleagues and fellows who have been concerned with the findings described herein. We thank them for their many contributions to the concepts derived and expressed. We also thank Ms Joan Otto and Mrs Christine Anderson for their help in the preparation of the manuscript.

\section{References}

${ }^{1}$ Hudson REB. Surgical pathology of the conducting system of the heart. Br Heart J 1967;29:646-70.

${ }^{2}$ Anderson KR, Ho SY, Anderson RH. The location and vascular supply of the sinus node in the human heart. Br Heart J 1979;41:28-32.

${ }^{3}$ James TN. The sinus node. Am J Cardiol 1977;40:96586.

${ }^{4}$ German Pathological Society. Bericht über die Verhandlungen der XIV Tagung der Deutschen pathologischen Gesellschaft in Erlangen vom 4-6 April 1910. Z All Pathol Pathol Anat 1910;21:433-8.

5 Janse MJ, Anderson RH. Specialized internodal atrial pathways - fact or fiction. Eur J Cardiol 1974;2:11737.

6 Anderson RH, Becker AE. Anatomy of conducting tissues revisited. Br Heart J 1978;40,suppl:2-16.

${ }^{7}$ Anderson RH, Becker AE, Tranum-Jensen J, Janse MJ. Anatomico-electrophysiological correlations in the conduction system-a review $\mathrm{Br}$ Heart $J$ 1980;45:67-82.

8 James TN. The connecting pathways between the sinus node and the A-V node and between the right and the left atrium in the human heart. Am Heart J 1963;66:498-508.

${ }^{9}$ Isa L, Matturri L, Rossi L. Contributo isto-citologico al riconoscimento delle connessioni internodali atriali. $G$ 
Ital Cardiol 1976;6:1024-1032.

${ }^{10}$ Spach M, King TD, Barr RC, Boaz DE, Marrow MN, Giddens SH. Electrical potential distribution surrounding the atria during depolarization and repolarization the dog. Circ Res 1969;24:857-73.

"Spach MS, Lieberman M, Scott JG, Barr RC, Johnson EA, Kootsey JM. Excitation sequences of the atrial septum and AV node in isolated hearts of the dog and the rabbit. Circ Res 1971;29:156-72.

12 Spach MS, Miller III WT, Barr RC, Geselowitz DB. Electrophysiology of the internodal pathways: determining the difference between anisotropic cardiac muscle and a specialized tract system. In: Little RC, ed. Physiology of atrial pacemakers and connective tissues. Mount Kisco, New York: Futura Publishing Company, 1980:367-80.

${ }^{13}$ Becker AE, Anderson RH. Morphology of the human atrioventricular junctional area. In: Wellens $\mathrm{HJJ}$, Lie $\mathrm{KI}$, Janse MJ, eds. The conduction system of the heart-structure, function and clinical implications. New York: Lea and Febiger, 1976:263-86.

14 Wittig JH, De Leval MR, Stark J. Intraoperative mapping of atrial activation before, during and after Mustard's operation. J Thorac Cardiovasc Surg 1977;73:1-13.

15 Massing GK, James TN. Anatomical configuration of the His bundle and bundle branches in the human heart. Circulation 1976;53:609-21.

${ }^{16}$ Sealy WC, Gallagher JJ, Wallace AG. The surgical treatment of the Wolff-Parkinson-White syndrome. Evolution of improved methods of identification and interruption of the Kent bundle. Ann Thorac Surg 1976;22:443-57.

${ }^{17}$ Harrison L, Gallagher JJ, Kasell J, et al. Cryosurgical ablation of the A-V node-His bundle: a new method for producing A-V block. Circulation 1977;55:46370.

${ }^{18}$ Sealy WC, Gallagher JJ. The surgical approach to the septal area of the heart based on experience with 45 patients with Kent bundles. J Thor Cardiol Surg 1980;79:542-51.

${ }^{19}$ Ho SY, Monro JL, Anderson RH. The disposition of the sinus node in left-sided juxtaposition of the atrial appendage. Br Heart $J$ 1979;41:129-32.

${ }^{20}$ Dickinson DF, Wilkinson JL, Anderson KR, Smith A, Ho SY, Anderson RH. The cardiac conduction system in situs ambiguus. Circulation 1979;59:879-85.

${ }^{21}$ Gillette PC, Kugler JD, Garson A Jun, Gutgesell HP, Duff DF, McNamara DG. Mechanisms of cardiac arrhythmias after the Mustard operation for transposition of the great arteries. $A m$ J Cardiol 1980;45:1225-30.

${ }^{22}$ Ullal RR, Anderson RH, Lincoln C. Mustard's operation modified to avoid dysrhythmias and pulmonary and systemic venous obstruction. $J$ Thorac Cardiovasc Surg 1979;78:431-9.

${ }^{23}$ Soto B, Becker AE, Moulaert AJ, Lie JT, Anderson
RH. Classification of isolated ventricular septal defects. Br Heart J 1980;43:332-43.

${ }^{24}$ Milo S, Ho SY, Wilkinson JL, Anderson RH. The surgical anatomy and atrioventricular conduction tissues of hearts with isolated ventricular septal defects. $J$ Thorac Cardiovasc Surg 1980;79:244-55.

${ }^{25}$ Latham RA, Anderson RH. Anatomical variations in atrioventricular conduction system with reference to ventricular septal defects. Br Heart J 1972;34:185-90.

${ }^{26}$ Titus JL, Daugherty GW, Edwards JE. Anatomy of the atrioventricular conduction system in ventricular septal defect. Circulation 1963;28:72-81.

${ }^{27}$ Anderson RH, Monro JL, Ho SY, Smith A, Deverall PB. Les voies de conduction auriculo-ventriculaires dans le tetralogie de Fallot. Coeur 1977;8:793-807.

${ }^{28}$ Essed CE, Ho SY, Hunter S, Anderson RH. Atrioventricular conduction system in univentricular heart of right ventricular type with right-sided rudimentary chamber. Thorax 1980;35:123-7.

${ }^{29}$ Milo S, Ho SY, Macartney FJ, Wilkinson JL, et al. Straddling and overriding atrioventricular valves: morphology and classification. Am $J$ Cardiol 1979;44:1122-34.

${ }^{30}$ Anderson RH, Becker AE, Arnold R, Wilkinson JL. The conducting tissues in congenitally corrected transposition. Circulation 1974;50:911-24.

${ }^{31}$ Wenink ACG. Congenitally complete heart block with an interrupted Monckeberg sling. Eur J Cardiol 1979;9:89-99.

32 Thiene G, Nava $P$, Rossi L. The conducting tissue in corrected transposition in situs inversus. Eur J Cardiol 1977;6:57-70.

${ }^{33}$ Wilkinson JL, Smith A, Lincoln C, Anderson RH. The conducting tissues in congenitally corrected transposition with situs inversus. Br Heart $J$ 1978;40:41-8.

${ }^{34}$ Anderson RH, Arnold R, Thaper MK, Jones RS, Hamilton DI. Cardiac specialized tissues in hearts with an apparently single ventricular chamber (double inlet left ventricle). Am J Cardiol 1974;33:95-106.

${ }^{35}$ Wenink ACG. The conduction tissues in primitive ventricle with outlet chamber: two different possibilities. $J$ Thorac Cardiovasc Surg 1978;75:747-53.

${ }^{36}$ Becker AE, Wilkinson JL, Anderson RH. Atrioventricular conduction tissues: a guide in understanding the morphogenesis of the univentricular heart. In: Van Praagh R, Takao A, eds. Etiology and morphogenesis of congenital heart disease. Mount Kisco, New York: Futura Publishing Co, 1980:126-42.

${ }^{37}$ Wilkinson JL, Anderson RH, Arnold R, Hamilton DI, Smith A. The conducting tissues in primitive ventricular hearts without an outlet chamber. Circulation 1976;53:930-8.

${ }^{38}$ Essed CE, Ho SY, Shinebourne EA, Joseph MC, Anderson RH. Further observations on conduction tissues in univentricular hearts - surgical implications. Eur Heart J 1981;2:87-96. 